\title{
Predictive value of preoperative inflammatory response biomarkers for metabolic syndrome and post-PCNL systemic inflammatory response syndrome in patients with nephrolithiasis
}

\author{
Kun Tang ${ }^{1,2, *}$, Haoran Liu'1,2,*, Kehua Jiang ${ }^{1,2}$, Tao Ye ${ }^{1,2}$, Libin Yan ${ }^{1,2}$, Peijun Liü ${ }^{1,2}$, \\ Ding Xia ${ }^{1,2}$, Zhiqiang Chen ${ }^{1,2}$, Hua $X u^{1,2}$ and Zhangqun $\mathrm{Ye}^{1,2}$ \\ ${ }^{1}$ Department of Urology, Tongji Hospital, Tongji Medical College, Huazhong University of Science and Technology, Wuhan \\ 430030, China \\ ${ }^{2}$ Institute of Urology of Hubei Province, Wuhan 430030, China \\ *These authors have contributed equally to this work \\ Correspondence to: Hua XU, email: xuhuawhu@163.com \\ Keywords: inflammatory response biomarkers, nephrolithiasis, percutaneous nephrolithotomy, metabolic syndrome, systemic \\ inflammatory response syndrome \\ Received: March 06, $2017 \quad$ Accepted: July 12, $2017 \quad$ Published: August 18, 2017 \\ Copyright: Tang et al. This is an open-access article distributed under the terms of the Creative Commons Attribution License 3.0 \\ (CC BY 3.0), which permits unrestricted use, distribution, and reproduction in any medium, provided the original author and source \\ are credited.
}

\section{ABSTRACT}

Neutrophil to lymphocyte ratio (NLR), derived neutrophil to lymphocyte ratio (dNLR), platelet to lymphocyte ratio (PLR) and lymphocyte to monocyte ratio (LMR) were promising biomarkers used to predict diagnosis and prognosis in various inflammatory responses diseases and cancers. However, there have been no reports regarding these biomarkers in kidney stone patients. This study aimed to evaluate the predictive value of inflammatory biomarkers for metabolic syndrome (MetS) and postPCNL SIRS in nephrolithiasis patients. We retrospectively enrolled 513 patients with nephrolithiasis and 204 healthy controls. NLR, dNLR, LMR and PLR in nephrolithiasis patients were significantly higher than control group. Patients with renal stone have higher NLR, dNLR, LMR and PLR than those without. ROC curve analysis indicated NLR, dNLR, LMR and PLR for predicting patients with nephrolithiasis and MetS, displayed AUC of $0.730,0.717,0.627$ and 0.606 . Additionally, ROC curves, using post-PCNL SIRS as the end-point for NLR, dNLR, LMR and PLR with AUC of $0.831,0.813,0.723$ and 0.685. Multivariate analysis revealed that NLR, $d N L R$ represented independent factors for predicting post-PCNL SIRS. While LMR independently associated with MetS. These resluts demonstrate preoperative NLR, dNLR and LMR appears to be effective predictors of post-PCNL SIRS and LMR of MetS in nephrolithiasis patients.

\section{INTRODUCTION}

Nephrolithiasis is an increasingly common condition in the Asia with a prevalence of $10.6 \%$ and $7.1 \%$ in men and women, respectively, [1] thus causing a heavy economic burden. Additionally, there is an increased risk for patients with kidney stones to stones recurrence, chronic kidney disease (CKD), diabetes, cardiovascular diseases and renal cancer. Previous studies have identified some lifestyle factors, including MetS, as a risk factor for kidney stone formation and contributors to the recurrence of kidney stones.
Several results showed that inflammation plays a significant part in the initial stage and progression of kidney stones [2]. Besides local inflammatory diseases, a portion of patients with cancers can appear systemic inflammatory responses, which are characterized by changes of peripheral blood cell counts. Therefore, several circulating blood cell-based biomarkers including: neutrophil to lymphocyte ratio (NLR), derived neutrophil to lymphocyte ratio (dNLR), [3] platelet to lymphocyte ratio (PLR) and lymphocyte to monocyte ratio (LMR) were used to predict diagnosis and prognosis in various diseases. These markers can be readily calculated from 
routine complete blood counts from peripheral blood specimens in the clinical practice. Furthermore, they are routinely measured and inexpensive to test, and hence potentially provide readily available objective information to help doctors to estimate patient progression.

The relationship between inflammatory biomarkers and various diseases has been demonstrated by numerous studies, highlighting the potential of preoperative inflammatory biomarkers [4-8]. However, to date, there have been no reports regarding NLR in kidney stone patients.

Previous epidemiological studies have shown an increased prevalence of kidney stones in patients with lifestyle-related systemic diseases such as hypertension [9]. diabetes mellitus, [10] obesity [11] and dyslipidemia. Taken together, these risk factors are termed metabolic syndrome (MetS). Furthermore, associations between nephrolithiasis and atherosclerosis, [12] cardiovascular disease, [13] renal cell carcinoma [14] have been recognized, and patients are at risk of these diseases after stone formation (Figure 1).

Interestingly, preoperative inflammatory response biomarkers, such as NLR, are considered to be strong predictors of these diseases, including hypertension, [4] obesity, [5] diabetes mellitus, [6] dyslipidemia, [15] MetS, $[5,8,16]$ atherosclerosis, [17] cardiovascular disease, [18] stroke, [19] and renal carcinoma [7]. Aggregate evidence suggests kidney stone formation becomes increasingly prevalent in people with MetS [20-22]. This association seems to be reciprocal in nature as patients with kidney stones seem to harbor MetS and ones with MetS are at increased risk for kidney stones (Figure 1) [12]. Owing to the complex causal relationship between MetS and nephrolithiasis, we investigated the predictive role of inflammation biomarkers for MetS-comorbidities in kidney stones

Percutaneous nephrolithotomy (PCNL) is one of the most common treatments for large renal and upper ureteric calculi [23]. For patients undergoing PCNL, there is a high possibility of developing systemic inflammatory response syndrome (SIRS), bacteremia and urosepsis [24]. Up to $35 \%$ of patients with complicated stones may develop SIRS, with a small percent progressing to sepsis [13]. Notably, in large cohort studies, sepsis was reported to be the most common cause of perioperative mortality following PCNL [25]. Previous researches reported that stone size, stone culture, and pelvic urine culture are crucial risk factors for SIRS following PCNL [23]. The present clinical parameters for predicting the post-PCNL SIRS infection are white cell counts, C-reaction protein (CRP) and procalcitonin (PCT), however, CRP and PCT are not routinely tested in our clinical practice, especially in the context of preoperative testing. And the pre-treatment white cell counts had limited role in predicting the post-PCNL SIRS.

We hypothesized the elevated NLR in patients with kidney stone, especially for patients with MetS comorbidities, and could play as a potential predictor of post-PCNL SIRS. However, the association between kidney stone and preoperative inflammatory response biomarkers, such as NLR, dNLR, LMR and PLR still remained unknown. The current research thus aimed to evaluate the clinical significance of the NLR, dNLR, LMR and PLR for detecting MetS, SIRS and to determine whether these biomarkers could serve as a predictor for MetS comorbidities and post-PCNL SIRS in patients with kidney stones.

\section{RESULTS}

\section{Basic characteristics of the study sample}

The clinicopathological characteristics of patients and healthy controls are presented in Table 1. Patients with kidney stones had a median age of 52 years (range: 19-84), with a gender ratio of 1.75:1 men to women. The median age in the healthy control group was 51 years (range: 19-79) with a gender ratio of 1.7:1 (men:women) Three were no statistically significant differences between the age and gender of the two groups $(\mathrm{P}>0.05)$.

Table 1 also shows the laboratory and clinical characteristics of the groups. Levels of diabetes, ASA score, neutrophil, lymphocyte, monocyte, platelet, hemoglobin, alkaline phosphatase, FBG, sodium, chloride, uric acid, serum creatinine, BUN and GFR were significantly different in kidney stone group compared with the healthy control group (all $\mathrm{P}<0.05$ ). In terms of white blood cell counts, albumin, total cholesterol, calcium, potassium and bicarbonate, no significant differences were found between the two groups.

\section{NLR, dNLR, LMR and PLR levels were increased in kidney stone patients}

There was a statistically significant difference in NLR, dNLR and LMR between the patients with kidney stones and healthy controls (all P $<0.001$ ), while the PLR was found to be comparable between the two groups. We found that patients with kidney stones had higher NLR and dNLR than the healthy controls $(\mathrm{P}<0.001)$ (Table 1 , Figure 2). The kidney stone patients also had significantly lower LMR level ( $\mathrm{P}<0.001)$ (Table 1, Figure 2).

\section{ROC curves of NLR, dNLR, LMR and PLR for the identification of kidney stone patients from healthy control}

ROC curve analysis suggested that NLR, dNLR and LMR had limited utility for the identification of patients with kidney stones based on area under the curve (AUC) values of 0.648 [95\% confidence interval (CI): 0.604-0.692], 0.625 (0.58-0.67), 0.662 (0.621-0.703) respectively (Figure 2, $\mathrm{P}<0.001$ ). PLR could not identify patients with kidney stone patients from healthy controls (AUC 0.53 (0.483-0.578), $\mathrm{P}=0.206$ (Figure 2). 
Table 1: Basic characteristics of the study sample

\begin{tabular}{|c|c|c|c|}
\hline Variables & $\begin{array}{l}\text { Kideny stone formers } \\
\qquad \mathrm{N}=\mathbf{5 1 3}\end{array}$ & $\begin{array}{l}\text { Healthy controls } \\
\qquad \mathbf{N}=\mathbf{2 0 4}\end{array}$ & P value \\
\hline NLR & $2.31 \pm 1.70$ & $1.61 \pm 0.56$ & $<0.001$ \\
\hline dNLR & $1.59 \pm 0.98$ & $1.22 \pm 0.40$ & $<0.001$ \\
\hline LMR & $4.17 \pm 1.60$ & $5.09 \pm 1.63$ & $<0.001$ \\
\hline PLR & $122.90 \pm 57.21$ & $126.37 \pm 52.37$ & 0.454 \\
\hline Age, (years) & $52.27 \pm 10.95$ & $50.81 \pm 11.91$ & 0.118 \\
\hline Gender, (male\%) & $294(57.31 \%)$ & $120(58.5)$ & 0.731 \\
\hline BMI, $\left(\mathrm{kg} / \mathrm{m}^{2}\right)$ & $23.2 \pm 3.08$ & $22.418 \pm 3$ & $<0.001$ \\
\hline Hypertension, n (\%) & $43(8.4 \%)$ & $0(0 \%)$ & $<0.001$ \\
\hline KillipI, n (\%) & $487(94.3 \%)$ & $204(100 \%)$ & $<0.001$ \\
\hline KillipII, n (\%) & $22(4.3 \%)$ & $0(0 \%)$ & \\
\hline KillipIII, n (\%) & $4(0.7 \%)$ & $0(0 \%)$ & \\
\hline KillipIV, n (\%) & $0(0 \%)$ & $0(0 \%)$ & \\
\hline Diabetes, n (\%) & $87(20 \%)$ & $0(0 \%)$ & $<0.001$ \\
\hline ASA $1, \mathrm{n}(\%)$ & $218(42.5 \%)$ & $151(74 \%)$ & $<0.001$ \\
\hline ASA2, n (\%) & $265(51.7 \%)$ & $53(26 \%)$ & \\
\hline ASA3, n (\%) & $30(5.8 \%)$ & $0(0 \%)$ & \\
\hline White blood cell, $\left(10^{9} / \mathrm{L}\right)$ & $6.12 \pm 1.65$ & $5.98 \pm 1.32$ & 0.270 \\
\hline Neutrophil, $\left(10^{9} / \mathrm{L}\right)$ & $3.66 \pm 1.39$ & $3.23 \pm 0.99$ & $<0.001$ \\
\hline Lymphocyte, $\left(10^{9} / \mathrm{L}\right)$ & $1.8 \pm 0.55$ & $2.12 \pm 0.57$ & $<0.001$ \\
\hline Monocyte, $\left(10^{9} / \mathrm{L}\right)$ & $0.48 \pm 0.19$ & $0.43 \pm 0.12$ & 0.009 \\
\hline Platelet, $\left(10^{9} / \mathrm{L}\right)$ & $201.92 \pm 64.04$ & $249.95 \pm 77.48$ & $<0.001$ \\
\hline Hemoglobin, (g/L) & $126.11 \pm 22.4$ & $138.38 \pm 26.78$ & $<0.001$ \\
\hline Alkaline phosphatase, (IU/L) & $69.61 \pm 23.45$ & $59.34 \pm 18.49$ & $<0.001$ \\
\hline Albumin, $(\mathrm{g} / \mathrm{L})$ & $40.99 \pm 26.55$ & $42.48 \pm 3.76$ & 0.425 \\
\hline Total Cholesterol, $(\mathrm{mmol} / \mathrm{L})$ & $4.07 \pm 0.82$ & $4.09 \pm 0.67$ & 0.714 \\
\hline $\mathrm{FBG},(\mathrm{mmol} / \mathrm{L})$ & $5.33 \pm 1.24$ & $4.89 \pm 0.64$ & $<0.001$ \\
\hline Sodium, $(\mathrm{mmol} / \mathrm{L})$ & $140.76 \pm 4.14$ & $141.92 \pm 2.15$ & $<0.001$ \\
\hline Chloride, $(\mathrm{mmol} / \mathrm{L})$ & $105.06 \pm 3.60$ & $104.41 \pm 2.20$ & 0.015 \\
\hline Calcium, (mmol/L) & $2.39 \pm 1.70$ & $2.32 \pm 0.13$ & 0.553 \\
\hline Potassium, (mmol/L) & $4.65 \pm 8.47$ & $4.29 \pm 0.39$ & 0.540 \\
\hline Bicarbonate, $(\mathrm{mmol} / \mathrm{L})$ & $24.24 \pm 4.72$ & $24.91 \pm 2.53$ & 0.056 \\
\hline Uric acid, (umol/L) & $365.53 \pm 121.62$ & $312.39 \pm 76.23$ & $<0.001$ \\
\hline Serum creatinine, (umol/L) & $139.86 \pm 152.49$ & $77.47 \pm 7.13$ & $<0.001$ \\
\hline BUN, (mol/L) & $7.43 \pm 5.79$ & $5.45 \pm 4.16$ & $<0.001$ \\
\hline $\mathrm{GFR},(\mathrm{ml} / \mathrm{min})$ & $67.87 \pm 30.39$ & $102.03 \pm 20.77$ & $<0.001$ \\
\hline
\end{tabular}

NLR, neutrophil to lymphocyte ratio; dNLR, neutrophil to (white cell count- neutrophil count) ratio; LMR, lymphocyte to monocyte ratio; PLR, platelet count to lymphocyte ratio; BMI, body mass index; ASA, American Society of Anesthesiologists; FBG, fasting blood-glucose; BUN, blood urea nitrogen; GFR, glomerular filtration rate. 
NLR, dNLR, LMR and PLR levels were increased in patients with MetS and post-PCNL SIRS

There was a statistically significant difference in NLR, dNLR, LMR and PLR in patients with kidney stones with MetS and post-PCNL SIRS compared to those without (all $\mathrm{P}<0.001$ ). We found that the patients with kidney stones had higher NLR, dNLR and PLR than healthy controls $(\mathrm{P}<0.001)$ (Table 2, Figures $3 \& 4)$, while LMR was significantly lower $(\mathrm{P}<0.001)$ (Table 2 , Figures $3 \& 4)$.

\section{Correlations of NLR, dNLR, LMR and PLR with clinical characteristics of kidney stone patients}

In Spearman correlation analysis, there were statistically significant positive correlations between NLR,
dNLR, LMR, PLR and MetS and post-PCNL SIRS (All P $<0.05$ ) (Table 3).

\section{Correlations of NLR, dNLR, LMR and PLR} with MetS and post-PCNL SIRS in patients with kidney stone

In Spearman correlation analysis, there were statistically significant positive correlations between MetS and NLR, dNLR, LMR, PLR, BMI, hypertension, Killip level, diabetes, ASA score, neutrophil, lymphocyte counts, total cholesterol, FBG and operative time (Table 4).

In addition, by spearman correlation analysis there were statistically significant positive correlations between post-PCNL SIRS and NLR, dNLR, LMR, PLR, gender, white blood cell, neutrophil, lymphocyte, monocyte counts, hemoglobin, total cholesterol, FBG, calcium, bicarbonate, serum creatinine, BUN, GFR, stone burden,

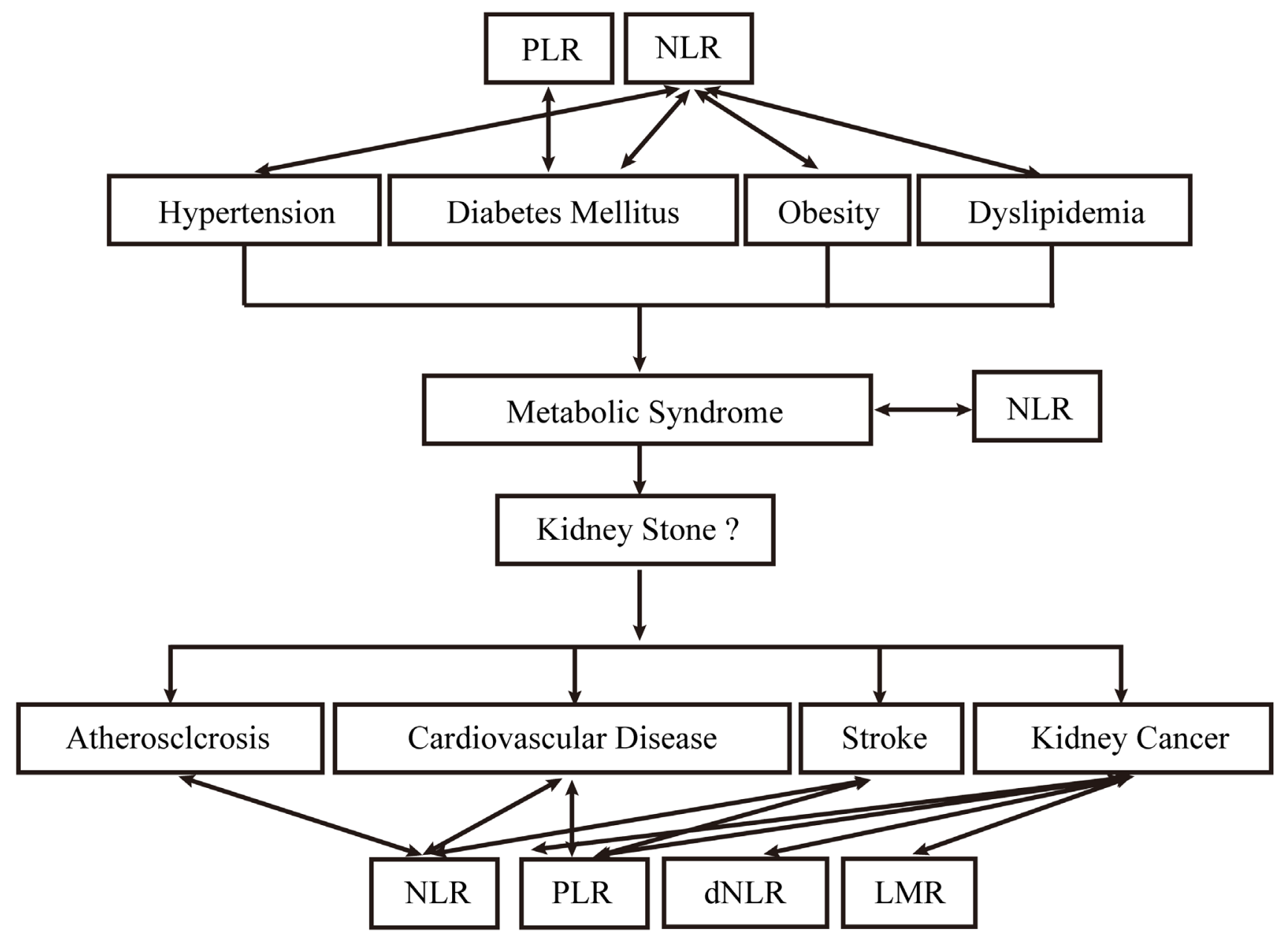

Figure 1: Etiological and complicated diseases of kidney stone and their association with NLR, dNLR, LMR and PLR. 

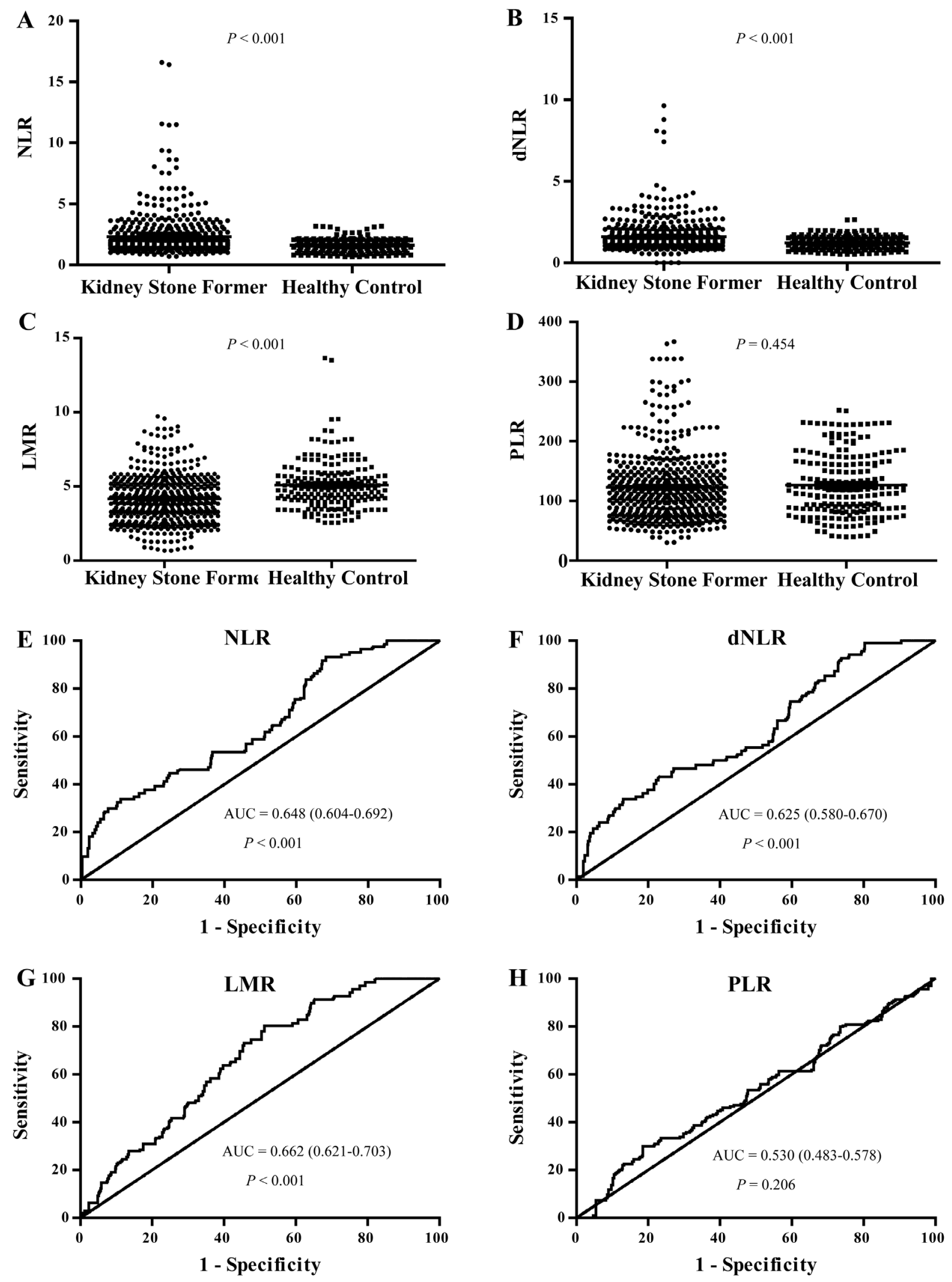

Figure 2: NLR, dNLR, LMR and PLR levels in kidney stone patients and their ROC curves for the identification of kidney stone patients. (A, B, C, D) showed the NLR, dNLR, LMR and PLR levels in kidney stone patients compared with the healthy control group, respectively. (E, F, G, H) showed the ROC curves of NLR, dNLR, LMR and PLR for the identification of kidney stone patients, respectively. 
Table 2: Clinical characteristics in kidney stone patients with or without SIRS and MetS

\begin{tabular}{|c|c|c|c|c|c|c|}
\hline Variables & $\begin{array}{c}\operatorname{SIRS}(+) \\
\mathrm{N}=181\end{array}$ & $\begin{array}{l}\text { SIRS(-) } \\
\mathbf{N}=332\end{array}$ & P value & $\begin{array}{c}\text { MetS(+) } \\
\mathbf{N}=\mathbf{8 3}\end{array}$ & $\begin{array}{c}\text { MetS(-) } \\
N=430\end{array}$ & P value \\
\hline NLR & $3.42 \pm 2.42$ & $1.70 \pm 0.50$ & $<0.001$ & $3.03 \pm 2.00$ & $2.17 \pm 1.61$ & $<0.001$ \\
\hline dNLR & $2.23 \pm 1.38$ & $1.25 \pm 0.33$ & $<0.001$ & $2.16 \pm 1.50$ & $1.49 \pm 0.80$ & $<0.001$ \\
\hline LMR & $3.42 \pm 1.52$ & $4.58 \pm 1.49$ & $<0.001$ & $3.60 \pm 1.25$ & $4.28 \pm 1.64$ & $<0.001$ \\
\hline PLR & $149.55 \pm 14.95$ & $108.37 \pm 22.54$ & $<0.001$ & $145.10 \pm 79.55$ & $118.61 \pm 20.99$ & $<0.001$ \\
\hline Age, (years) & $52.48 \pm 11.1$ & $52.15 \pm 10.86$ & 0.739 & $53.1 \pm 10.2$ & $52.1 \pm 11.1$ & 0.426 \\
\hline Gender, (male, \%) & $92(50.83 \%)$ & $202(60.84 \%)$ & 0.028 & $31(37.35 \%)$ & $263(61.16 \%)$ & $<0.001$ \\
\hline BMI, $\left(\mathrm{kg} / \mathrm{m}^{2}\right)$ & $23.1 \pm 3.08$ & $23.28 \pm 3.09$ & 0.529 & $25.3 \pm 2.68$ & $22.8 \pm 3$ & $<0.001$ \\
\hline Hypertension, n (\%) & $32(17.86 \%)$ & $59(17.77 \%)$ & 0.979 & $56(67.47 \%)$ & $55(12.79 \%)$ & $<0.001$ \\
\hline KillipI, n (\%) & $171(94.48 \%)$ & $312(93.98 \%)$ & 0.019 & $73(87.95 \%)$ & $410(95.35 \%)$ & 0.006 \\
\hline KillipII, n (\%) & $6(3.31 \%)$ & $16(4.82 \%)$ & & $8(9.64 \%)$ & $14(3.26 \%)$ & \\
\hline KillipIII, n (\%) & $4(2.21 \%)$ & $0(0 \%)$ & & $2(2.41 \%)$ & $2(0.47 \%)$ & \\
\hline Diabetes, n (\%) & $30(16.57 \%)$ & $57(17.17 \%)$ & 0.864 & $53(63.86 \%)$ & $45(10.47 \%)$ & $<0.001$ \\
\hline ASA $1, n(\%)$ & $78(43.09 \%)$ & $138(41.57 \%)$ & 0.944 & $14(16.87 \%)$ & $202(46.98 \%)$ & $<0.001$ \\
\hline ASA2, n (\%) & $93(51.38 \%)$ & $172(51.81 \%)$ & & $63(75.90 \%)$ & $202(46.98 \%)$ & \\
\hline ASA3, n $(\%)$ & $10(5.52 \%)$ & $20(6.02 \%)$ & & $4(4.82 \%)$ & $26(6.05 \%)$ & \\
\hline White blood cell, $\left(10^{9} / \mathrm{L}\right)$ & $6.61 \pm 1.79$ & $5.86 \pm 1.5$ & $<0.001$ & $6.56 \pm 1.85$ & $6.04 \pm 1.59$ & $<0.001$ \\
\hline Neutrophil, $\left(10^{9} / \mathrm{L}\right)$ & $4.45 \pm 1.64$ & $3.22 \pm 1.01$ & $<0.001$ & $4.30 \pm 1.60$ & $3.53 \pm 1.31$ & $<0.001$ \\
\hline Lymphocyte, $\left(10^{9} / \mathrm{L}\right)$ & $1.52 \pm 0.5$ & $1.95 \pm 0.52$ & $<0.001$ & $1.61 \pm 0.53$ & $1.84 \pm 0.55$ & $<0.001$ \\
\hline Monocyte, $\left(10^{9} / \mathrm{L}\right)$ & $0.51 \pm 0.23$ & $0.46 \pm 0.16$ & 0.003 & $0.49 \pm 0.20$ & $0.47 \pm 0.19$ & 0.531 \\
\hline Platelet, $\left(10^{9} / \mathrm{L}\right)$ & $202.82 \pm 66.01$ & $201.43 \pm 63.03$ & 0.814 & $211.40 \pm 41.72$ & $200.09 \pm 60.66$ & 0.141 \\
\hline Hemoglobin, (g/L) & $120.7 \pm 24.08$ & $129.06 \pm 20.88$ & $<0.001$ & $128.93 \pm 20.72$ & $125.57 \pm 22.69$ & 0.212 \\
\hline $\begin{array}{l}\text { Alkaline phosphatase, } \\
\text { (IU/L) }\end{array}$ & $68.68 \pm 25.38$ & $70.11 \pm 22.35$ & 0.511 & $65.61 \pm 21.55$ & $70.38 \pm 23.74$ & 0.090 \\
\hline Albumin, (g/L) & $37.91 \pm 5.45$ & $42.67 \pm 32.65$ & 0.053 & $38.21 \pm 4.26$ & $41.53 \pm 28.91$ & 0.297 \\
\hline Total Cholesterol, (mmol/L) & $3.93 \pm 0.30$ & $4.15 \pm 0.84$ & 0.004 & $4.23 \pm 0.78$ & $4.04 \pm 0.82$ & 0.050 \\
\hline FBG, $(\mathrm{mmol} / \mathrm{L})$ & $5.37 \pm 1.05$ & $5.31 \pm 1.34$ & 0.595 & $6.12 \pm 1.65$ & $5.18 \pm 1.09$ & $<0.001$ \\
\hline Sodium, $(\mathrm{mmol} / \mathrm{L})$ & $140.79 \pm 2.88$ & $140.75 \pm 4.7$ & 0.926 & $141.42 \pm 2.93$ & $140.64 \pm 4.33$ & 0.116 \\
\hline Chloride, $(\mathrm{mmol} / \mathrm{L})$ & $105.14 \pm 4.04$ & $105.03 \pm 3.34$ & 0.731 & $105.04 \pm 4.30$ & $105.07 \pm 3.45$ & 0.947 \\
\hline Calcium, (mmol/L) & $2.22 \pm 0.12$ & $2.48 \pm 2.10$ & 0.094 & $2.69 \pm 2.85$ & $2.33 \pm 1.36$ & 0.076 \\
\hline Potassium, $(\mathrm{mmol} / \mathrm{L})$ & $4.24 \pm 0.59$ & $4.06 \pm 0.43$ & 0.422 & $4.25 \pm 0.70$ & $4.73 \pm 9$ & 0.633 \\
\hline Bicarbonate, (mmol/L) & $23.49 \pm 5.82$ & $24.66 \pm 3.95$ & 0.007 & $24.15 \pm 3.62$ & $24.26 \pm 4.91$ & 0.839 \\
\hline Uric acid,(umol/L) & $364.19 \pm 138.22$ & $366.26 \pm 111.75$ & 0.854 & $376.26 \pm 137.77$ & $363.46 \pm 118.32$ & 0.380 \\
\hline Serum creatinine, $(\mathrm{umol} / \mathrm{L})$ & $161.76 \pm 182.64$ & $127.92 \pm 132.00$ & 0.016 & $157.18 \pm 196.62$ & $136.52 \pm 142.45$ & 0.259 \\
\hline $\mathrm{BUN},(\mathrm{mol} / \mathrm{L})$ & $8.04 \pm 7.05$ & $7.1 \pm 4.95$ & 0.078 & $8.13 \pm 6.42$ & $7.30 \pm 5.66$ & 0.235 \\
\hline $\mathrm{GFR},(\mathrm{ml} / \mathrm{min})$ & $62.2 \pm 31.69$ & $70.97 \pm 29.24$ & 0.002 & $63.72 \pm 29.72$ & $68.67 \pm 30.49$ & 0.174 \\
\hline
\end{tabular}

(Continued) 


\begin{tabular}{lcccccc}
\hline Variables & $\begin{array}{c}\text { SIRS(+) } \\
\text { N=181 }\end{array}$ & $\begin{array}{c}\text { SIRS(-) } \\
\text { N=332 }\end{array}$ & P value & $\begin{array}{c}\text { MetS(+) } \\
\text { N=83 }\end{array}$ & $\begin{array}{c}\text { MetS(-) } \\
\text { N=430 }\end{array}$ & P value \\
\hline Stone burden, $\left(\mathrm{mm}^{2}\right)$ & $283.11 \pm 248.48$ & $204.96 \pm 198.76$ & $<0.001$ & $253.75 \pm 258.07$ & $262.87 \pm 11.78$ & 0.881 \\
Operative time, (minutes) & $120 \pm 15$ & $117 \pm 49.3$ & 0.008 & $138 \pm 49.5$ & $117 \pm 127$ & 0.002 \\
Stay length, (days) & $28.28 \pm 2.83$ & $14 \pm 5.5$ & $<0.001$ & $17 \pm 2.8$ & $15 \pm 7.8$ & 0.049 \\
Multiple nephrolith, n (\%) & $171(94.48 \%)$ & $263(80.78 \%)$ & $<0.001$ & $68(81.93 \%)$ & $373(86.74 \%)$ & 0.247 \\
Staghorn nephrolith, n (\%) & $34(25.97 \%)$ & $48(14.41 \%)$ & $<0.001$ & $18(21.69 \%)$ & $78(18.14 \%)$ & 0.448 \\
Hydronephrosis, n (\%) & $177(97.79 \%)$ & $290(87.09 \%)$ & $<0.001$ & $67(80.72 \%)$ & $400(93.02 \%)$ & $<0.001$ \\
\hline
\end{tabular}

NLR, neutrophil to lymphocyte ratio; dNLR, neutrophil to (white cell count- neutrophil count) ratio; LMR, lymphocyte to monocyte ratio; PLR, platelet count to lymphocyte ratio; BMI, body mass index; ASA, American Society of Anesthesiologists; FBG, fasting blood-glucose; BUN, blood urea nitrogen; GFR, glomerular filtration rate, SIRS, systemic inflammatory response syndrome; MetS, metabolic syndrome.

operative time, stay length, multiple nephrolith, staghorn nephrolith and hydronephrosis (Table 4).

\section{ROC curves of NLR, dNLR, LMR and PLR for the predicating of MetS and Post-PCNL SIRS in patients with kidney stone}

ROC curves, utilizing MetS as the end-point for NLR, dNLR, LMR and PLR, are depicted in Figure 3. The areas under the curve (AUC) for NLR, dNLR, PLR and LMR were $0.730,0.717,0.627$ and 0.606 , respectively (All $\mathrm{P}<0.01$ ).

In addition, ROC curves, using post-PCNL SIRS as the end-point for NLR, dNLR, LMR and PLR, are shown in Figure 4. The areas under the curve (AUC) for NLR, dNLR, PLR and LMR were 0.831, 0.813, 0.723 and 0.685, respectively (All $\mathrm{P}<0.001$ ).

\section{The univariate and multivariate cox analyses of NLR, dNLR, LMR and PLR for the predicating of MetS and post-PCNL SIRS in patients with kidney stone}

Table 5 describes the univariate and multivariate Cox proportional hazards analyses in patients with kidney stones. Univariate Cox proportional hazards analysis, factors associated with MetS included the NLR, dNLR, LMR, PLR, BMI, hypertension, Killip level, diabetes, ASA score, White blood cell, Neutrophil, Lymphocyte counts, Total cholesterol, FBG and Operative time, Stay length, Hydronephrosis (all $\mathrm{P}<0.05$ ). After extensive univariate analysis, significant variables included in the multivariable Cox proportional hazards models, which showed that the level of LMR (HR 0.602, 95\%CI 0.461 0.785), BMI (HR 1.435, 95\%CI 1.260 1.633), Diabetes (HR 8.858, 95\%CI 3.636 21.579), ASA score (HR 2.552, 95\%CI 1.452 4.485), Lymphocyte (HR 0.207, 95\%C: 0.048 0.891), total cholesterol (HR 1.586,
95\% CI 1.093 2.302) and operative time (HR 1.010, $95 \%$ CI 1.004 1.016) were significant predictors of MetS comorbidities.

Additionally, via univariate Cox proportional hazards analysis factors associated with post-PCNL SIRS included the NLR, dNLR, LMR, PLR, gender, hypertension, Killip level, white blood cell, neutrophil, lymphocyte, monocyte counts, hemoglobin, total cholesterol, bicarbonate, GFR, stone burden, operative time, stay length, multiple nephrolith, staghorn nephrolith and hydronephrosis (all $\mathrm{P}<0.05$ ). After extensive univariate analysis, these significant variables were included in the multivariable Cox proportional hazards models, which showed that the level of NLR (HR 6.743, 95\%CI 3.947 11.518), dNLR $(\mathrm{HR}=7.844,95 \% \mathrm{CI} 4.257 \sim 14.455)$, White blood cell (HR 1.339, 95\%CI 1.168 1.535), Neutrophil (HR 3.131, 95\%CI 2.305 4.251), Lymphocyt (HR 0.081, 95\%CI 0.041 0.163), Albumin (HR 1.090, 95\%CI 1.006 1.181), Bicarbonat (HR 0.915, 95\%CI 0.846 0.990), Stay length (HR 1.072, 95\%CI 1.021 1.125), Multiple nephrolith (HR 2.988, 95\%CI 1.039 8.59) and Hydronephrosis (HR $16.288,95 \%$ CI $4.332 \sim 61.234$ ) were significant predictors of post-PCNL SIRS.

\section{DISCUSSION}

Nephrolithiasis is a common disease whose recurrence rates are up to $50 \%$ and $80 \%$ within the first five and ten years, respectively, after an initial stone episode. To our knowledge, this is the first research to evaluate NLR, dNLR, LMR and PLR as the predictors of kidney stone. Our study indicates, a significant correlation between inflammation biomarkers and kidney stones. Patients with kidney stone have higher NLR, dNLR, LMR and PLR levels than healthy controls. Additionally, patients with MetS, post-PCNL SIRS have higher NLR, dNLR, LMR and PLR levels than those without. We also demonstrated that increased pre-operation NLR, 
dNLR, LMR and PLR positively correlated with MetS comorbidities and post-PCNL SIRS in patients with kidney stones. The Cox regression multivariate analyses indicated that NLR appeared to be potentially independent useful inflammatory biomarker of in patients with kidney stone, and could serve as a new inflammatory markers for monitoring disease activity, especially for patients with
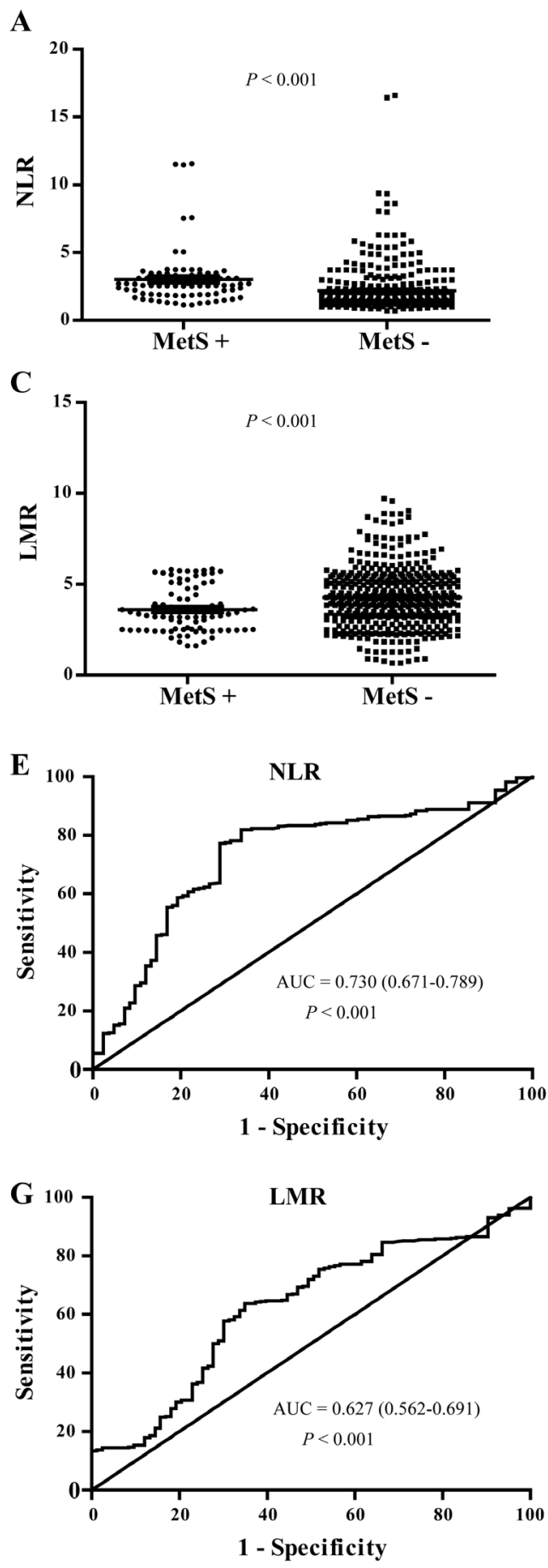

kidney stones in critical care following PCNL. Although dNLR, PLR and LMR were significantly associated with survival in univariate analysis, they were not maintained as independent indicators in the multivariate model. These results were supported by several mechanisms of inflammatory reactions to kidney stones.
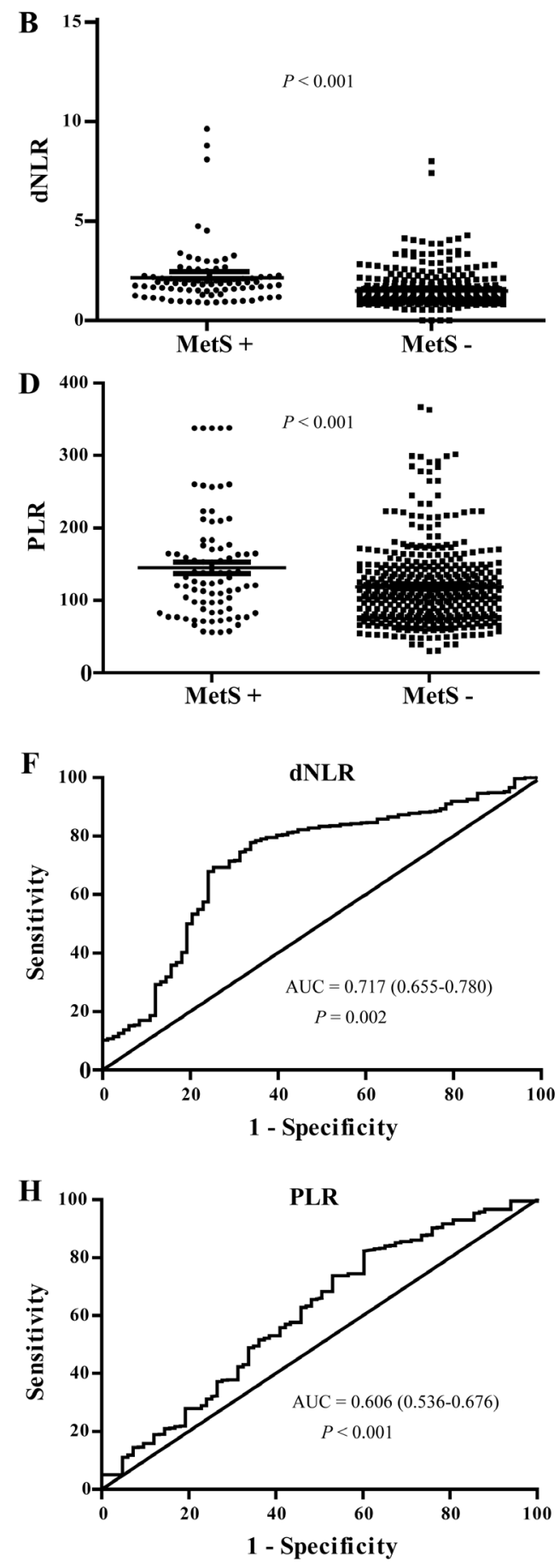

Figure 3: NLR, dNLR, LMR and PLR levels in kidney stone patients with and without MetS, and their ROC curves of for the predicating of MetS. (A, B, C, D) showed the NLR, dNLR, LMR and PLR levels in kidney stone patients with or without MetS, respectively. (E, F, G, H) showed the ROC curves of NLR, dNLR, LMR and PLR for the predicating of MetS in kidney stone patients, respectively. 
MetS has been recognized as one of the most relevant clinical components associated with kidney stone. It is known that MetS is associated with systemic inflammation and in patients with MetS, the risk for development of kidney stone increases. In patients with kidney stones and metabolic syndrome who had PCNL. Also, MetS was associated with deterioration of renal function in the long-term follow-up, [26] The estimated

$$
\text { A }
$$

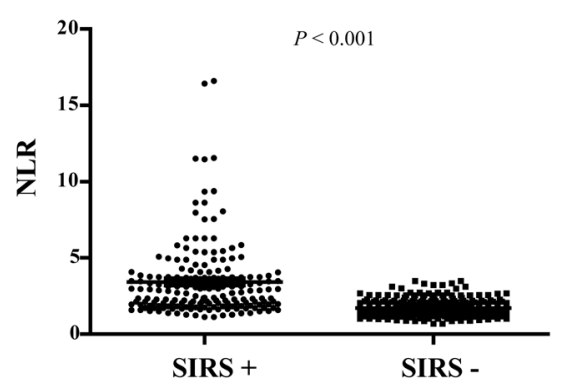

$$
\text { C }
$$
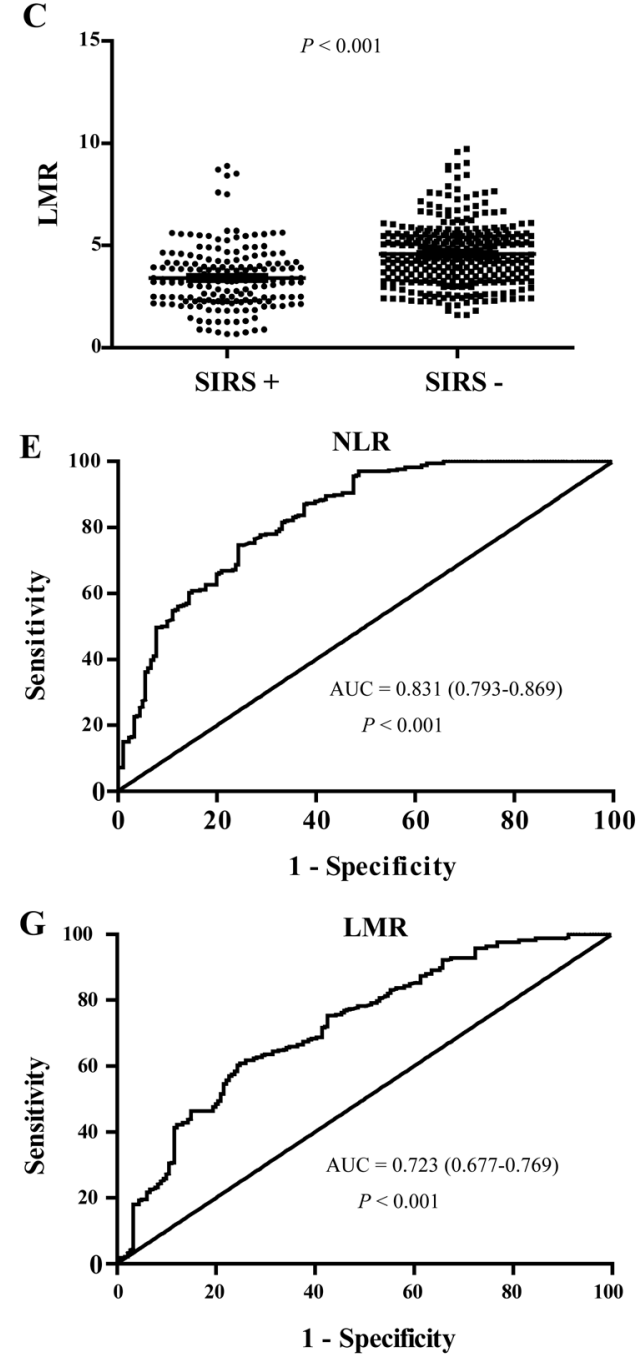

prevalence of MetS in patients with kidney stone is $4.7 \%$ to $20.7 \%,[27,28]$ and the prevalence of MetS in our study is $16.2 \%$. In the present study, we reported that inflammatory markers NLR, dNLR, LMR and PLR were higher in kidney stone patients with than without MetS comorbidities. This result indicates that the presence of MetS in patients with kidney stones is associated with more intense systemic inflammation. The results may
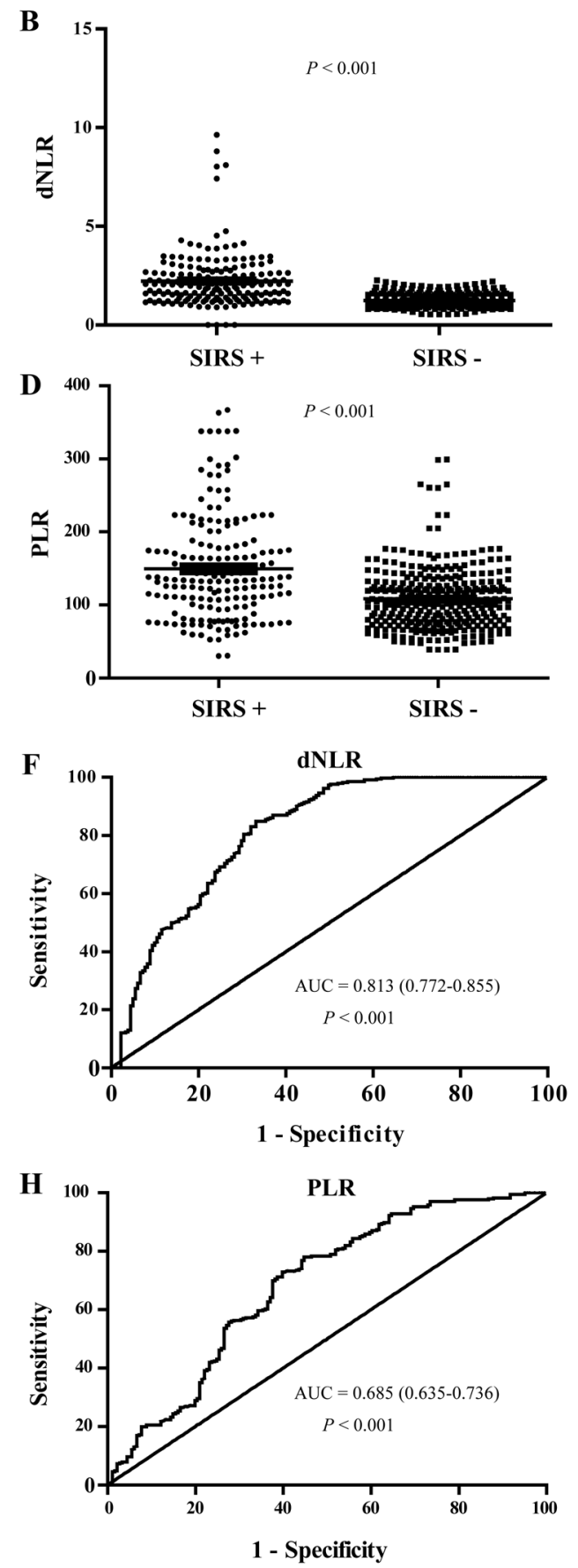

Figure 4: NLR, dNLR, LMR and PLR levels in kidney stone patients with and without post-PCNL SIRS, and their ROC curves for the predicating of post-PCNL SIRS. (A, B, C, D) showed the NLR, dNLR, LMR and PLR levels in kidney stone patients with or without post-PCNL SIRS, respectively. (E, F, G, H) showed the ROC curves of NLR, dNLR, LMR and PLR for the predicating of post-PCNL SIRS in kidney stone patients, respectively. 
Table 3: Correlations of NLR, dNLR, LMR and PLR with clinical characteristics of kidney stone patients

\begin{tabular}{|c|c|c|c|c|c|c|c|c|}
\hline \multirow{2}{*}{ Variables } & \multicolumn{2}{|c|}{ NLR } & \multicolumn{2}{|c|}{ dNLR } & \multicolumn{2}{|c|}{ LMR } & \multicolumn{2}{|c|}{ PLR } \\
\hline & $\mathbf{R}^{2}$ & P value & $\mathbf{R}^{2}$ & P value & $\mathbf{R}^{2}$ & P value & $\mathbf{R}^{2}$ & Pvalue \\
\hline Age, (years) & 0.020 & 0.293 & 0.001 & 0.451 & $<0.001$ & 0.959 & 0.002 & 0.267 \\
\hline Gender, (male\%) & 0.009 & 0.033 & 0.009 & 0.035 & 0.009 & 0.029 & 0.017 & 0.003 \\
\hline Residence, (urban) & 0.003 & 0.206 & 0.002 & 0.330 & 0.004 & 0.175 & $<0.001$ & 0.937 \\
\hline BMI, (kg/m2) & 0.003 & 0.200 & 0.008 & 0.044 & 0.002 & 0.289 & $<0.001$ & 0.622 \\
\hline Hypertension & 0.001 & 0.999 & 0.002 & 0.273 & 0.006 & 0.084 & 0.002 & 0.306 \\
\hline Killip Level & 0.003 & 0.248 & 0.001 & 0.463 & 0.003 & 0.207 & 0.002 & 0.294 \\
\hline Diabetes & 0.020 & 0.001 & 0.030 & $<0.001$ & 0.002 & 0.330 & 0.011 & 0.015 \\
\hline ASA & 0.002 & 0.287 & 0.002 & 0.313 & 0.001 & 0.382 & 0.008 & 0.050 \\
\hline White blood cell, $\left(10^{9} / \mathrm{L}\right)$ & 0.166 & $<0.001$ & 0.147 & $<0.001$ & 0.052 & $<0.001$ & 0.002 & 0.377 \\
\hline Neutrophil, $\left(10^{9} / \mathrm{L}\right)$ & 0.480 & $<0.001$ & 0.467 & $<0.001$ & 0.156 & $<0.001$ & 0.051 & $<0.001$ \\
\hline Lymphocyte, $\left(10^{9} / \mathrm{L}\right)$ & 0.287 & $<0.001$ & 0.265 & $<0.001$ & 0.236 & $<0.001$ & 0.376 & $<0.001$ \\
\hline Monocyte, $\left(10^{9} / \mathrm{L}\right)$ & 0.054 & $<0.001$ & 0.007 & 0.062 & 0.389 & $<0.001$ & 0.003 & 0.247 \\
\hline Platelet, $\left(10^{9} / \mathrm{L}\right)$ & $<0.001$ & 0.877 & 0.001 & 0.474 & $<0.001$ & 0.999 & 0.328 & $<0.001$ \\
\hline Hemoglobin, $(\mathrm{g} / \mathrm{L})$ & 0.044 & $<0.001$ & 0.037 & $<0.001$ & 0.019 & 0.002 & 0.090 & $<0.001$ \\
\hline Alkaline phosphatase, (IU/L) & 0.002 & 0.347 & 0.001 & 0.9712 & $<0.001$ & 0.987 & 0.001 & 0.424 \\
\hline Albumin, $(\mathrm{g} / \mathrm{L})$ & 0.005 & 0.118 & 0.005 & 0.102 & 0.002 & 0.280 & 0.003 & 0.249 \\
\hline Total Cholesterol, (mmol/L) & 0.006 & 0.084 & 0.003 & 0.192 & 0.021 & 0.001 & 0.015 & 0.005 \\
\hline $\mathrm{FBG},(\mathrm{mmol} / \mathrm{L})$ & 0.011 & 0.017 & 0.016 & 0.004 & 0.005 & 0.117 & 0.007 & 0.062 \\
\hline Sodium, $(\mathrm{mmol} / \mathrm{L})$ & $<0.001$ & 0.968 & $<0.001$ & 0.6425 & 0.004 & 0.170 & 0.004 & 0.142 \\
\hline Chloride, $(\mathrm{mmol} / \mathrm{L})$ & $<0.001$ & 0.608 & 0.003 & 0.213 & 0.008 & 0.040 & 0.001 & 0.538 \\
\hline Calcium, $(\mathrm{mmol} / \mathrm{L})$ & 0.002 & 0.292 & 0.002 & 0.255 & 0.000 & 0.742 & 0.001 & 0.408 \\
\hline Potassium, $(\mathrm{mmol} / \mathrm{L})$ & 0.0013 & 0.424 & 0.001 & 0.445 & 0.001 & 0.563 & 0.003 & 0.209 \\
\hline Bicarbonate, (mmol/L) & 0.002 & 0.313 & $<0.001$ & 0.768 & 0.013 & 0.010 & 0.001 & 0.382 \\
\hline Uric acid, (umol/L) & 0.010 & 0.026 & $<0.001$ & 0.608 & 0.013 & 0.010 & 0.016 & 0.005 \\
\hline Serum creatinine, (umol/L) & 0.049 & $<0.001$ & 0.027 & $<0.001$ & 0.038 & $<0.001$ & 0.004 & 0.147 \\
\hline $\mathrm{BUN},(\mathrm{mol} / \mathrm{L})$ & 0.045 & $<0.001$ & 0.015 & 0.005 & 0.037 & $<0.001$ & $<0.001$ & 0.996 \\
\hline GFR, (ml/min) & 0.037 & $<0.001$ & 0.012 & 0.012 & 0.047 & $<0.001$ & 0.003 & 0.256 \\
\hline Stone burden, $\left(\mathrm{mm}^{2}\right)$ & 0.007 & 0.053 & 0.006 & 0.086 & 0.004 & 0.133 & 0.003 & 0.253 \\
\hline SIRS & 0.233 & $<0.001$ & 0.228 & $<0.001$ & 0.121 & $<0.001$ & 0.119 & $<0.001$ \\
\hline MS & 0.035 & $<0.001$ & 0.065 & $<0.001$ & 0.025 & $<0.001$ & 0.029 & $<0.001$ \\
\hline Operative time, (minutes) & $<0.001$ & 0.827 & $<0.001$ & 0.945 & $<0.001$ & 0.677 & $<0.001$ & 0.530 \\
\hline Stay length, (days) & 0.030 & $<0.001$ & 0.029 & $<0.001$ & 0.004 & 0.176 & 0.011 & 0.020 \\
\hline Multiple nephrolith & 0.006 & 0.070 & 0.004 & 0.141 & 0.013 & 0.001 & 0.004 & 0.152 \\
\hline Staghorn nephrolith & 0.024 & $<0.001$ & 0.031 & $<0.001$ & 0.004 & 0.163 & 0.013 & 0.009 \\
\hline Hydronephrosis & 0.005 & 0.120 & 0.003 & 0.214 & 0.008 & 0.039 & 0.002 & 0.350 \\
\hline
\end{tabular}

NLR, neutrophil to lymphocyte ratio; dNLR, neutrophil to (white cell count- neutrophil count) ratio; LMR, lymphocyte to monocyte ratio; PLR, platelet count to lymphocyte ratio; BMI, body mass index; ASA, American Society of Anesthesiologists; FBG, fasting bloodglucose; BUN, blood urea nitrogen; GFR, glomerular filtration rate, SIRS, systemic inflammatory response syndrome; MetS, metabolic syndrome. 
Table 4: Correlations of NLR, dNLR, LMR and PLR with MetS and post-PCNL SIRS in patients with kidney stone

\begin{tabular}{|c|c|c|c|c|c|c|}
\hline \multirow{2}{*}{ Variables } & \multicolumn{2}{|l|}{ SIRS } & \multirow[b]{2}{*}{ P value } & \multicolumn{2}{|c|}{ MetS } & \multirow[b]{2}{*}{ P value } \\
\hline & $95 \% \mathrm{CI}$ & $\mathbf{R}$ & & $95 \% \mathrm{CI}$ & $\mathbf{R}$ & \\
\hline NLR & 0.411 to 0.545 & 0.481 & $<0.001$ & 0.103 to 0.270 & 0.188 & $<0.001$ \\
\hline dNLR & 0.405 to 0.540 & 0.476 & $<0.001$ & 0.174 to 0.337 & 0.257 & $<0.001$ \\
\hline LMR & -0.420 to -0.266 & -0.345 & $<0.001$ & -0.223 to -0.052 & -0.139 & $<0.001$ \\
\hline PLR & 0.267 to 0.420 & 0.346 & $<0.001$ & 0.081 to 0.250 & 0.166 & $<0.001$ \\
\hline Age, (years) & -0.072 to 0.101 & 0.015 & 0.738 & -0.052 to 0.121 & 0.035 & 0.426 \\
\hline Gender, (male\%) & -0.182 to -0.010 & -0.097 & 0.028 & -0.260 to -0.092 & -0.177 & $<0.001$ \\
\hline Residence, (urban) & -0.151 to 0.022 & -0.065 & 0.140 & -0.123 to 0.049 & -0.037 & 0.400 \\
\hline BMI, (kg/m2) & -0.114 to 0.059 & -0.028 & 0.529 & 0.215 to 0.373 & 0.296 & $<0.001$ \\
\hline Hypertension & -0.088 to 0.085 & -0.001 & 0.979 & 0.055 to 0.226 & 0.142 & $<0.001$ \\
\hline Killip Level & -0.090 to 0.083 & -0.004 & 0.933 & 0.336 to 0.480 & 0.411 & $<0.001$ \\
\hline Diabetes & -0.036 to 0.138 & 0.051 & 0.248 & 0.055 to 0.226 & 0.142 & 0.001 \\
\hline ASA & -0.112 to 0.061 & -0.025 & 0.566 & 0.120 to 0.286 & 0.204 & $<0.001$ \\
\hline White blood cell, $\left(10^{9 / \mathrm{L})}\right.$ & 0.034 to 0.205 & 0.121 & 0.006 & -0.125 to 0.048 & -0.039 & 0.383 \\
\hline Neutrophil, $\left(10^{9} / \mathrm{L}\right)$ & 0.346 to 0.489 & 0.420 & $<0.001$ & 0.118 to 0.284 & 0.203 & $<0.001$ \\
\hline Lymphocyte, $\left(10^{9} / \mathrm{L}\right)$ & -0.442 to -0.292 & -0.369 & $<0.001$ & -0.236 to -0.067 & -0.153 & 0.001 \\
\hline Monocyte, $\left(10^{9} / \mathrm{L}\right)$ & 0.043 to 0.213 & 0.129 & 0.003 & -0.059 to 0.114 & 0.028 & 0.531 \\
\hline Platele,t $\left(10^{9} / \mathrm{L}\right)$ & -0.076 to 0.097 & 0.010 & 0.814 & -0.022 to 0.151 & 0.065 & 0.141 \\
\hline Hemoglobin, (g/L) & -0.261 to -0.094 & -0.179 & $<0.001$ & -0.031 to 0.141 & -0.055 & 0.212 \\
\hline Alkaline phosphatase, (IU/L) & -0.115 to 0.058 & -0.029 & 0.511 & -0.161 to 0.012 & -0.075 & 0.090 \\
\hline Albumin, (g/L) & -0.171 to 0.001 & -0.086 & 0.053 & -0.132 to 0.041 & -0.046 & 0.297 \\
\hline Total Cholesterol, (mmol/L) & -0.220 to -0.045 & -0.133 & 0.004 & 0.000 to 0.172 & 0.087 & 0.049 \\
\hline $\mathrm{FBG},(\mathrm{mmol} / \mathrm{L})$ & 0.001 to 0.177 & 0.089 & 0.043 & 0.198 to 0.357 & 0.279 & $<0.001$ \\
\hline Sodium, (mmol/L) & -0.132 to 0.041 & -0.002 & 0.2979 & -0.114 to 0.060 & 0.028 & 0.536 \\
\hline Chloride, (mmol/L) & -0.071 to 0.102 & 0.015 & 0.731 & -0.089 to 0.084 & -0.003 & 0.947 \\
\hline Calcium, (mmol/L) & -0.194 to -0.018 & -0.107 & 0.016 & -0.008 to 0.164 & 0.079 & 0.076 \\
\hline Potassium, (mmol/L) & -0.122 to 0.051 & -0.036 & 0.422 & -0.107 to 0.0657 & -0.021 & 0.633 \\
\hline Bicarbonate, $(\mathrm{mmol} / \mathrm{L})$ & -0.203 to -0.032 & -0.118 & 0.007 & -0.096 to 0.078 & -0.009 & 0.839 \\
\hline Uric acid, (umol/L) & -0.095 to 0.079 & -0.008 & 0.854 & -0.048 to 0.125 & 0.039 & 0.380 \\
\hline Serum creatinine, (umol/L) & 0.020 to 0.191 & 0.106 & 0.016 & -0.037 to 0.136 & 0.050 & 0.259 \\
\hline BUN, (mol/L) & 0.005 to 0.177 & 0.092 & 0.039 & -0.034 to 0.139 & 0.053 & 0.235 \\
\hline $\mathrm{GFR},(\mathrm{ml} / \mathrm{min})$ & -0.222 to -0.052 & -0.138 & 0.002 & -0.146 to 0.027 & 0.060 & 0.174 \\
\hline Stone burden, $\left(\mathrm{mm}^{2}\right)$ & 0.082 to 0.251 & 0.028 & $<0.001$ & -0.101 to 0.073 & -0.0140 & 0.755 \\
\hline Operative time, (minutes) & 0.017 to 0.189 & 0.104 & 0.020 & 0.071 to 0.241 & 0.157 & $<0.001$ \\
\hline Stay length, (days) & 0.188 to 0.349 & 0.271 & $<0.001$ & -0.009 to 0.163 & 0.078 & 0.080 \\
\hline Multiple nephrolith & 0.098 to 0.266 & 0.183 & $<0.001$ & -0.149 to 0.025 & -0.062 & 0.159 \\
\hline Staghorn nephrolith & 0.060 to 0.230 & 0.146 & 0.001 & -0.062 to 0.110 & 0.013 & 0.580 \\
\hline Hydronephrosis & 0.089 to 0.257 & 0.175 & $<0.001$ & -0.108 to 0.065 & -0.021 & 0.629 \\
\hline
\end{tabular}

NLR, neutrophil to lymphocyte ratio; dNLR, neutrophil to (white cell count- neutrophil count) ratio; LMR, lymphocyte to monocyte ratio; PLR, platelet count to lymphocyte ratio; BMI, body mass index; ASA, American Society of Anesthesiologists; FBG, fasting blood-glucose; BUN, blood urea nitrogen; GFR, glomerular filtration rate, SIRS, systemic inflammatory response syndrome; MetS, metabolic syndrome. 
Table 5: The univariate and multivariate Cox analyses of NLR, dNLR, LMR and PLR for the predicating of MetS and post-PCNL SIRS in patients with kidney stone

\begin{tabular}{|c|c|c|c|c|c|c|c|c|c|c|c|c|}
\hline \multirow{2}{*}{ Variables } & \multicolumn{3}{|c|}{$\begin{array}{c}\text { SIRS } \\
\text { (Univariate analysis) }\end{array}$} & \multicolumn{3}{|c|}{$\begin{array}{c}\text { SIRS } \\
\text { (Multivariate analysis) }\end{array}$} & \multicolumn{3}{|c|}{$\begin{array}{c}\text { MS } \\
\text { (Univariate analysis) }\end{array}$} & \multicolumn{3}{|c|}{$\begin{array}{c}\text { MS } \\
\text { (Multivariate analysis) }\end{array}$} \\
\hline & HR & $95 \% \mathrm{CI}$ & $\begin{array}{c}P \\
\text { value }\end{array}$ & HR & $95 \% \mathrm{CI}$ & $\begin{array}{c}P \\
\text { value }\end{array}$ & HR & $95 \% \mathrm{CI}$ & Pvalue & HR & $95 \% \mathrm{CI}$ & $\begin{array}{c}P \\
\text { value }\end{array}$ \\
\hline NLR & 5.764 & $4.038 \sim 8.227$ & $<0.001$ & 6.743 & $3.947 \sim 11.518$ & $<0.001$ & 1.246 & $1.107 \sim 1.402$ & $<0.001$ & 0.943 & $0.762 \sim 1.168$ & 0.593 \\
\hline dNLR & 10.896 & $6.676 \sim 17.782$ & $<0.001$ & 7.844 & $4.257 \sim 14.455$ & $<0.001$ & 1.744 & $1.370 \sim 2.220$ & $<0.001$ & 1.893 & $1.277 \sim 0.861$ & 0.225 \\
\hline LMR & 0.571 & $0.492 \sim 0.662$ & $<0.001$ & 0.995 & $0.803 \sim 1.235$ & 0.967 & 0.743 & $0.629 \sim 0.877$ & $<0.001$ & 0.602 & $0.461 \sim 0.785$ & $<0.001$ \\
\hline PLR & 1.014 & $1.010 \sim 1.018$ & $<0.001$ & 1.001 & $0.995 \sim 1.007$ & 0.781 & 1.007 & $1.003 \sim 1.011$ & $<0.001$ & 1.005 & $0.998 \sim 1.011$ & 0.142 \\
\hline Age, (years) & 1.003 & $0.986 \sim 1.020$ & 0.738 & l & l & I & 1.009 & $0.987 \sim 1.031$ & 0.426 & I & / & / \\
\hline Gender, (male\%) & 1.109 & $0.769 \sim 1.601$ & 0.579 & / & 1 & I & 0.930 & $0.579 \sim 1.492$ & 0.763 & I & I & l \\
\hline Residence, (urban) & 0.760 & $0.527 \sim 1.094$ & 0.140 & l & / & / & 0.815 & $0.507 \sim 1.311$ & 0.400 & I & I & / \\
\hline BMI, (kg/m2) & 0.981 & $0.925 \sim 1.041$ & 0.528 & l & l & / & 1.332 & $1.218 \sim 1.455$ & $<0.001$ & 1.435 & $1.260 \sim 1.633$ & $<0.001$ \\
\hline Hypertension & 2.218 & $1.4518 \sim 3.389$ & $<0.001$ & 1.665 & $0.898 \sim 3.086$ & 0.106 & 4.195 & $2.550 \sim 3.902$ & $<0.001$ & 1.919 & $0.973 \sim 3.786$ & 0.060 \\
\hline Killip Level & 1.465 & $0.761 \sim 2.824$ & 0.253 & l & I & I & 2.795 & $1.403 \sim 5.566$ & 0.003 & 1.278 & $0.483 \sim 3.382$ & 0.622 \\
\hline Diabetes & 0.979 & $0.602 \sim 1.592$ & 0.932 & l & I & I & 8.987 & $5.282 \sim 15.290$ & $<0.001$ & 8.858 & $3.636 \sim 21.579$ & $<0.001$ \\
\hline ASA & 0.916 & $0.679 \sim 1.236$ & 0.565 & l & l & / & 2.433 & $1.646 \sim 3.596$ & $<0.001$ & 2.552 & $1.452 \sim 4.485$ & $<0.001$ \\
\hline White blood cell, $\left(10^{9} / \mathrm{L}\right)$ & 1.326 & $1.182 \sim 1.488$ & $<0.001$ & 1.339 & $1.168 \sim 1.535$ & $<0.001$ & 1.201 & $1.047 \sim 1.379$ & 0.009 & 1.718 & $0.458 \sim 6.447$ & 0.423 \\
\hline Neutrophil, $\left(10^{9} / \mathrm{L}\right)$ & 2.072 & $1.747 \sim 2.458$ & $<0.001$ & 3.131 & $2.305 \sim 4.251$ & $<0.001$ & 1.416 & $1.214 \sim 1.653$ & $<0.001$ & 0.806 & $0.166 \sim 3.907$ & 0.789 \\
\hline Lymphocyte, $\left(10^{9} / \mathrm{L}\right)$ & 0.190 & $0.125 \sim 0.288$ & $<0.001$ & 0.081 & $0.041 \sim 0.163$ & $<0.001$ & 0.450 & $0.285 \sim 0.711$ & 0.001 & 0.207 & $0.048 \sim 0.891$ & 0.034 \\
\hline Monocyte, $\left(10^{9} / \mathrm{L}\right)$ & 3.775 & $1.227 \sim 11.620$ & $<0.021$ & 0.831 & $0.107 \sim 6.423$ & 0.859 & 1.462 & $0.446 \sim 4.793$ & 0.530 & / & / & l \\
\hline Platelet, $\left(10^{9} / \mathrm{L}\right)$ & 1.000 & $0.998 \sim 1.003$ & 0.814 & / & l & / & 1.003 & $0.999 \sim 1.006$ & 0.141 & I & l & l \\
\hline Hemoglobin, (g/L) & 0.983 & $0.975 \sim 0.991$ & $<0.001$ & 0.988 & $0.973 \sim 1.004$ & 0.144 & 1.007 & $0.996 \sim 1.018$ & 0.211 & l & l & / \\
\hline Alkaline phosphatase, (IU/L) & 0.997 & $0.990 \sim 1.005$ & 0.511 & / & / & l & 0.091 & $0.979 \sim 1.002$ & 0.091 & I & l & / \\
\hline Albumin, (g/L) & 0.949 & $0.912 \sim 0.988$ & 0.010 & 1.090 & $1.006 \sim 1.181$ & 0.035 & 0.977 & $0.929 \sim 1.027$ & 0.358 & / & / & / \\
\hline Total Cholesterol, (mmol/L) & 0.778 & $0.6191 \sim 0.979$ & 0.033 & 0.836 & $0.600 \sim 1.166$ & 0.291 & 1.477 & $1.124 \sim 1.941$ & 0.005 & 1.586 & $1.093 \sim 2.302$ & 0.015 \\
\hline FBG, $(\mathrm{mmol} / \mathrm{L})$ & 1.039 & $0.901 \sim 1.199$ & 0.595 & / & l & / & 1.690 & $1.387 \sim 2.059$ & $<0.001$ & 1.179 & $0.902 \sim 1.541$ & 0.227 \\
\hline Sodium, $(\mathrm{mmol} / \mathrm{L})$ & 1.002 & $0.959 \sim 1.047$ & 0.926 & / & l & / & 1.071 & $0.986 \sim 1.165$ & 0.106 & l & l & l \\
\hline Chloride, $(\mathrm{mmol} / \mathrm{L})$ & 1.009 & $0.959 \sim 1.061$ & 0.731 & / & I & I & 0.998 & $0.935 \sim 1.065$ & 0.947 & I & I & l \\
\hline Calcium, (mmol/L) & 0.205 & $0.053 \sim 0.784$ & 0.021 & 0.838 & $0.406 \sim 1.732$ & 0.634 & 1.089 & $0.982 \sim 1.205$ & 0.109 & / & / & / \\
\hline Potassium $(\mathrm{mmol} / \mathrm{L})$ & 0.987 & $0.951 \sim 1.024$ & 0.480 & / & / & / & 0.988 & $0.937 \sim 1.042$ & 0.665 & / & / & l \\
\hline Bicarbonate, $(\mathrm{mmol} / \mathrm{L})$ & 0.940 & $0.898 \sim 0.984$ & 0.008 & 0.915 & $0.846 \sim 0.990$ & 0.027 & 0.995 & $0.945 \sim 1.047$ & 0.838 & / & / & / \\
\hline Uric acid, (umol/L) & 1.000 & $0.998 \sim 1.001$ & 0.854 & / & l & / & 1.001 & $0.999 \sim 1.003$ & 0.380 & I & I & / \\
\hline Serum creatinine, (umol/L) & 1.001 & $1.000 \sim 1.003$ & 0.200 & / & / & l & 1.001 & $0.999 \sim 1.002$ & 0.263 & I & / & I \\
\hline $\mathrm{BUN},(\mathrm{mol} / \mathrm{L})$ & 1.027 & $0.997 \sim 1.059$ & 0.082 & I & I & I & 1.022 & $0.986 \sim 1.060$ & 0.238 & I & / & l \\
\hline $\mathrm{GFR},(\mathrm{ml} / \mathrm{min})$ & 0.991 & $0.985 \sim 0.997$ & 0.002 & 1.002 & $0.990 \sim 1.013$ & 0.780 & 0.995 & $0.987 \sim 1.002$ & 1.002 & / & / & l \\
\hline Stone burden, $\left(\mathrm{mm}^{2}\right)$ & 1.002 & $1.001 \sim 1.003$ & $<0.001$ & 1.001 & $1.000 \sim 1.002$ & 0.133 & 1.000 & $0.999 \sim 1.001$ & 0.881 & I & / & l \\
\hline Operative time, (minutes) & 1.004 & $1.001 \sim 1.008$ & 0.021 & 0.999 & $0.993 \sim 1.005$ & 0.783 & 1.008 & $1.003 \sim 1.013$ & 0.001 & 1.010 & $1.004 \sim 1.016$ & 0.002 \\
\hline Stay length, (days) & 1.098 & $1.063 \sim 1.134$ & $<0.001$ & 1.072 & $1.021 \sim 1.125$ & 0.005 & 1.030 & $0.996 \sim 1.065$ & 0.083 & l & / & l \\
\hline Multiple nephrolith & 4.020 & $2.008 \sim 8.048$ & $<0.001$ & 2.988 & $1.039 \sim 8.59$ & 0.042 & 0.642 & $0.348 \sim 1.184$ & 0.156 & l & / & l \\
\hline Staghorn nephrolith & 2.127 & $1.351 \sim 3.347$ & 0.001 & 1.052 & $0.505 \sim 2.194$ & 0.892 & 1.181 & $0.656 \sim 2.125$ & 0.579 & I & / & / \\
\hline Hydronephrosis & 8.512 & $3.6260 \sim 19.983$ & $<0.001$ & 16.288 & $4.332 \sim 61.234$ & $<0.001$ & 0.620 & $0.345 \sim 1.114$ & 0.110 & I & l & / \\
\hline
\end{tabular}

NLR, neutrophil to lymphocyte ratio; dNLR, neutrophil to (white cell count- neutrophil count) ratio; LMR, lymphocyte to monocyte ratio; PLR, platelet count to lymphocyte ratio; BMI, body mass index; ASA, American Society of Anesthesiologists; FBG, fasting blood-glucose; BUN, blood urea nitrogen; GFR, glomerular filtration rate, SIRS, systemic inflammatory response syndrome; MetS, metabolic syndrome. 
have clinical importance, because the inflammation factors indicating MetS in kidney stone may be early markers of developing cardiovascular events.

Previous researches have reported that even with careful preparation before operation, SIRS occurs in 11\%$35 \%$ of patients following PCNL and progress to sepsis in $2.5 \%$ of patients $[29,30]$. In our study, the total SIRS occurrence rate was $35.3 \%$ in patients with larger stones and obstructed pelvicalyceal system, consistent with findings reported by Bag et al with the risk of $49 \%$ [31].

The relationship between elevated pre-operative NLR, dNLR, LMR and PLR and kidney stones is yet to be elucidated. Firstly, neutrophil was triggered by stonestimulated inflammatory factors, including the granulocyte colony stimulating factor, tumor necrosis factor-alpha, interleukin-6, and myeloid growth factors. Moreover, elevated circulating neutrophils have been reported prompt secretion of inflammatory mediators and therefore accelerate stone formation. Thus elevated neutrophils may aid in the formation of kidney stone by providing an adequate environment. Secondly, decreased lymphocyte count may also play an important roles in inflammatory reaction to stones. Known as an inflammatory response, neutrophil suppresses the immune response by inhibiting the cytolytic activity of immune cells such as lymphocytes, activated $T$ cells, and natural killer cells [32].

There is an intimate relationship between kidney stone and inflammatory cytokines. Extrapolating this to the microenvironment of the kidney, some investigators of pro-inflammatory state have found in the presence of molecules generally involved in inflammatory pathways, such as osteopontin, heavy chain of inter-alpha-inhibitor, collagen, and the zinc in the nephron, specifically in interstitial plaques of the renal papillae in stone formers $[33,34]$. Reactive oxygen species (ROS) and oxidative stress (OS) represent well-known factors that contribute to the progress of MetS and cardiovascular diseases [35, 36].

Finally, neutrophils play an important role both in pro- and anti-tumor functions in cancer and immunerelated disease progression. In two recent publications in Nature, Coffelt et al. reveal a novel mechanism that neutrophils and $\mathrm{T}$ cells cooperate to generate a metastasissupporting immune suppression, and Wculek et al. found that neutrophils have a fundamental role in inflammatory responses and their contribution to tumorigenesis [37]. These findings support the conclusion that elevated NLR could predict poor survival in cancer patients, and thus suggested to us that neutrophils may also play a similar role in the kidney stone formation and progression.

The possible advantage of this study was that it focused on the clinical utility of this type of laboratory biomarkers. For the kidney stone patients with higher risk of post-PCNL after evaluating preoperative NLR, careful preparation peri-operation and post-operative standard-of-care were recommended. It also raised the cost-effectiveness of routine blood test.
The current study has several limitations that should to be taken in account. Firstly, our results were from a retrospective design, single-center study and thus the predicative significance of systematic inflammatory biomarkers in patient's with kidney stones remains to be confirmed by prospective and clinical validation studies. Although we demonstrated the initial evidence that NLR, dNLR, LMR and PLR were increased in patients with kidney stone which were associated with post-PCNL SIRS and MS comorbidities, the NLR, dNLR, LMR and PLR were not predictors of kidney stone formation. Besides further basic studies will be carried out to identify the detailed mechanisms by which kidney stones mediate inflammatory cells responses and inflammatory mediators stimulated kidney stone formation and accumulation. Finally, since CRP and PCT are not routinely tested in our clinical practice, therefore CRP and PCT were not included in our analyses. Further researches should compare the predictive role between NLR, dNLR and CRP, PCT as well as clinicopathological parameters.

In conclusion, we demonstrate for the first time that NLR, dNLR, LMR and PLR are all increased in kidney stone patients, and positively correlated with MetS comorbidities and post-PCNL SIRS. In multivariate analysis, NLR appears to be potentially useful inflammatory biomarkers of systemic inflammation in patients with kidney stone, which suggests that increased NLR level before surgery was independent and adverse predictor of MS comorbidities and post-PCNL SIRS. We suggest that clinicians should consider the level of NLR before surgery to help select the most appropriate therapy plan for their patients with kidney stone, especially for operational evaluation in MetS comorbidities patients and monitoring the SIRS following PCNL.

\section{MATERIALS AND METHODS}

\section{Study population}

Retrospective investigation and analysis were carried out in patients with kidney stones who had PCNL at Tongji Hospital between January 2015 and December 2015. The inclusion criteria were as follows: 1) A CT and stone composition analysis was performed for all patients with a kidney stone; 2) Treated with PCNL; 3) No history of previous therapies or other malignancies; 4) No perioperative mortality; 5) No antibiotic treatment before surgery, infection and hyperpyrexia; 6) Preoperative blood parameter data available; 7) Informed consents were obtained from eligible patients. Exclusion criteria included: a previous placement of stent, nephrostomy tube or indwelling catheter, history of renal failure, fever prior to surgery, presence of infectious diseases on admission, previous interventional treatment, concomitant bladder stone or tumor, concomitant therapy 
with other antibiotics, the presence of contra-lateral renal or ureteral stone, and complicated with cyst and malignancy. Through this approach we successfully recruited 513 patients with kidney stones and 204 healthy controls in our study.

\section{Data collection}

For each patient and healthy control, we collected the following clinical and pathological information: age, gender, BMI, residence, hypertension, Killip level, diabetes, ASA score, stone characteristics (stone burden, multiple nephrolith, staghorn nephrolith and hydronephrosis) and perioperative variables (operation time and stay length and post-PCNL SIRS rates). All patients were performed routine blood tests (white blood cell, neutrophil, lymphocyte, monocyte, platelet counts, hemoglobin, alkaline phosphatase, albumin, total cholesterol, FBG, sodium, chloride, calcium, potassium, bicarbonate, BUN, uric acid, serum creatinine and GFR) and imaging test (plain radiography of kidneys, ureters and bladder (KUB), renal ultrasonography, ntravenous urography (IVU) or computed tomography (CT). Clinical parameters such as hydronephrosis were found by physical examination and confirmed by ultrasonography, CT or magnetic resonance imaging (MRI). Stone characteristics included the number of stones (detected via CT or MRI scan), staghorn (yes/ no), stone location and stone burden. Stone surface area (stone burden) was calculated by the following formula: length $\times$ width $\times \pi \times 0.25$ [38]. In cases of multiple calculi, stone burden was defined as the sum of the surface area of each stone.

\section{Definition}

Hematological parameters were obtained 1 week prior to kidney stone treatment. Preoperative NLR, dNLR, LMR and PLR were measured by peripheral blood cell count, and were described as follows: NLR = neutrophil to lymphocyte ratio; $\mathrm{dNLR}=$ neutrophil to (white cell count- neutrophil count) ratio; LMR = lymphocyte to monocyte ratio; and PLR = platelet count to lymphocyte ratio. MetS was defined as: individuals with 3 out of the 5 criteria of the National Cholesterol Education Program Adult Treatment Panel III (NCEP ATP III) were met, modified for pre-diabetes (fasting glucose 100-125 mg/dL) [39]. In the post-operative period, patients were monitored for signs of SIRS, as defied by the development of 2 of 5 criteria:(1) temperature less than 36 or over 38 , (2) heart rate more than 90 beats per minute, (3) tachypnea more than 20 breaths per minute, (4) white cell count more than $12 \times 10[9] / \mathrm{L}$ or more than $4 \times 10^{9} / \mathrm{L},(5)$ A systolic blood pressure below $90 \mathrm{mmHg}$ or decrease of $40 \mathrm{mmHg}$ below baseline in the presence of SIRS was defied as septic shock [40].

\section{Ethics}

This study was approved by the Medical Ethics Committee of Huazhong University of Science and Technology. Written informed consent was obtained from all participants.

\section{Statistical analyses}

Statistical analyses was performed using GraphPad Prism version 5.013 (San Diego, CA, USA), SPSS 2.0 (IBM Corporation, Armonk, NY, USA) and R software version 3.2.0 (http://www.r-project.org/). The optimal cut-off levels of NLR, dNLR, LMR, and PLR were determined by receiver operating curve (ROC) analysis. Associations of NLR, dNLR, PLR, and LMR with other clinicopathological factors were determined using student's t-test, chi-square test and linear-regression analysis. Univariate and multivariate analyses were determined by the Cox regression model. Variables that reached a level of statistical significance in the univariate analysis were included into the multivariable analysis. All statistical tests were two sided and p-values less than 0.05 $(p<0.05)$ were considered statistically significant unless otherwise specified.

\section{Author contributions}

Tang.K and Liu H.R are co-first authors. Tang.K contributed to initial study design and writing. Liu H.R and were responsible for data collection, data analysis and writing. Xu.H, Chen Z.Q, Ye Z.Q contributed to study design and editing. Tao Ye, Liu P.J, Yan L.B, Xia.D contributed to data interpretation and designing figures.

\section{ACKNOWLEDGMENTS}

This project was supported by the National Natural Science Foundation of China (31372562, 81270788, $81470935,81370805)$, the Chenguang Program of Wuhan Science and Technology Bereau (2015070404010199), and The National High Technology Research and Development Program 863 (2014AA020607).

\section{CONFLICTS OF INTEREST}

The authors declare no competing financial interests.

\section{REFERENCES}

1. Scales CD, Smith AC, Hanley JM, Saigal CS. Prevalence of kidney stones in the United States. Eur Urol. 2012; 62:160-165.

2. Mulay SR, Kulkarni OP, Rupanagudi KV, Migliorini A, Darisipudi MN, Vilaysane A, Muruve D, Shi Y, Munro F, Liapis H, Anders HJ. Calcium oxalate crystals induce renal 
inflammation by NLRP3-mediated IL-1beta secretion. J Clin Invest. 2013; 123:236-246.

3. Proctor MJ, McMillan DC, Morrison DS, Fletcher CD, Horgan PG, Clarke SJ. A derived neutrophil to lymphocyte ratio predicts survival in patients with cancer. Br J Cancer. 2012; 107:695-699.

4. Belen E, Sungur A, Sungur MA, Erdogan G. Increased neutrophil to lymphocyte ratio in patients with resistant hypertension. J Clin Hypertens. 2015; 17:532-537.

5. Bahadir A, Baltaci D, Turker Y, Turker Y, Iliev D, Ozturk S, Deler MH, Sariguzel YC. Is the neutrophil-to-lymphocyte ratio indicative of inflammatory state in patients with obesity and metabolic syndrome? Anatol J Cardiol. 2015; $15: 816-822$

6. Kahraman C, Kahraman NK, Aras B, Cosgun S, Gulcan E. The relationship between neutrophil-to-lymphocyte ratio and albuminuria in type 2 diabetic patients: a pilot study. Arch Med Sci. 2016; 12:571-575.

7. de Martino M, Pantuck AJ, Hofbauer S, Waldert M, Shariat SF, Belldegrun AS, Klatte T. Prognostic impact of preoperative neutrophil-to-lymphocyte ratio in localized nonclear cell renal cell carcinoma. J Urol. 2013; 190:1999-2004

8. Yasar Z, Buyuksirin M, Ucsular FD, Kargi A, Erdem F, Talay F, Kurt OK. Is an elevated neutrophil-to-lymphocyte ratio a predictor of metabolic syndrome in patients with chronic obstructive pulmonary disease? Eur Rev Med Pharmacol Sci. 2015; 19:956-962.

9. Madore F, Stampfer MJ, Rimm EB, Curhan GC. Nephrolithiasis and risk of hypertension. Am J Hypertens. 1998; 11:46-53.

10. Taylor EN, Stampfer MJ, Curhan GC. Diabetes mellitus and the risk of nephrolithiasis. Kidney Int. 2005; 68:1230-1235.

11. Taylor EN, Stampfer MJ, Curhan GC. Obesity, weight gain, and the risk of kidney stones. JAMA. 2005; 293:455-462.

12. Reiner AP, Kahn A, Eisner BH, Pletcher MJ, Sadetsky N, Williams OD, Polak JF, Jacobs DR Jr, Stoller ML. Kidney stones and subclinical atherosclerosis in young adults: the CARDIA study. J Urol. 2011; 185:920-925.

13. Lin SY, Lin CL, Chang YJ, Hsu WH, Lin CC, Wang IK, Chang CT, Chang CH, Lin MC, Kao CH. Association between kidney stones and risk of stroke: a nationwide population-based cohort study. Medicine (Baltimore). 2016; 95:e2847.

14. Cheungpasitporn W, Thongprayoon C, O'Corragain OA, Edmonds PJ, Ungprasert P, Kittanamongkolchai W, Erickson SB. The risk of kidney cancer in patients with kidney stones: a systematic review and meta-analysis. QJM. 2015; 108:205-212.

15. Chen J, Chen MH, Li S, Guo YL, Zhu CG, Xu RX, Zhang Y, Sun J, Qing P, Liu G, Li JJ. Usefulness of the neutrophilto-lymphocyte ratio in predicting the severity of coronary artery disease: a Gensini score assessment. J Atheroscler Thromb. 2014; 21:1271-1282.
16. Buyukkaya E, Karakas MF, Karakas E, Akcay AB, Tanboga IH, Kurt M, Sen N. Correlation of neutrophil to lymphocyte ratio with the presence and severity of metabolic syndrome. Clin Appl Thromb Hemost. 2014; 20:159-163.

17. Balta S, Celik T, Mikhailidis DP, Ozturk C, Demirkol S, Aparci M, Iyisoy A. The relation between atherosclerosis and the neutrophil-lymphocyte ratio. Clin Appl Thromb Hemost. 2016; 22:405-411.

18. Verdoia M, Schaffer A, Barbieri L, Aimaretti G, Marino P, Sinigaglia F, Suryapranata H, De Luca G. Impact of diabetes on neutrophil-to-lymphocyte ratio and its relationship to coronary artery disease. Diabetes Metab. 2015; 41:304-311.

19. Hyun S, Kwon S, Cho S, Park S, Jung W, Moon S, Park J, Ko C, Cho K. Can the neutrophil-to-lymphocyte ratio appropriately predict carotid artery stenosis in patients with ischemic stroke?-a retrospective study. J Stroke Cerebrovasc Dis. 2015; 24:2646-2651.

20. Lange JN, Mufarrij PW, Wood KD, Holmes RP, Assimos DG. The association of cardiovascular disease and metabolic syndrome with nephrolithiasis. Curr Opin Urol. 2012; 22:154-159.

21. Rendina D, De Filippo G, Mossetti G, Zampa G, Muscariello R, Benvenuto G, Vivona CL, Ippolito S, Galante F, Lombardi G, Biondi B, Strazzullo P. Relationship between metabolic syndrome and multinodular non-toxic goiter in an inpatient population from a geographic area with moderate iodine deficiency. J Endocrinol Invest. 2012; 35:407-412.

22. Jeong IG, Kang T, Bang JK, Park J, Kim W, Hwang SS, Kim HK, Park HK. Association between metabolic syndrome and the presence of kidney stones in a screened population. Am J Kidney Dis. 2011; 58:383-388.

23. Omar M, Noble M, Sivalingam S, El MA, Gamal A, Farag M, Monga M. Systemic inflammatory response syndrome after percutaneous nephrolithotomy: a randomized singleblind clinical trial evaluating the impact of irrigation pressure. J Urol. 2016; 196:109-114.

24. Erdil T, Bostanci Y, Ozden E, Atac F, Yakupoglu YK, Yilmaz AF, Sarikaya S. Risk factors for systemic inflammatory response syndrome following percutaneous nephrolithotomy. Urolithiasis. 2013; 41:395-401.

25. Fuller A, Razvi H, Denstedt JD, Nott L, Hendrikx A, Luke M, Pal SK, de la Rosette J. The clinical research office of the endourological society percutaneous nephrolithotomy global study: outcomes in the morbidly obese patient - a case control analysis. Can Urol Assoc J. 2014; 8:E393-397.

26. Akman T, Binbay M, Erbin A, Tepeler A, Sari E, Kucuktopcu O, Ozgor F, Muslumanoglu A. The impact of metabolic syndrome on long-term outcomes of percutaneous nephrolithotomy (PCNL). BJU Int. 2012; 110:E1079-1083.

27. Sakhaee K, Capolongo G, Maalouf NM, Pasch A, Moe OW, Poindexter J, Adams-Huet B. Metabolic syndrome and the 
risk of calcium stones. Nephrol Dial Transplant. 2012; 27:3201-3209.

28. West B, Luke A, Durazo-Arvizu RA, Cao G, Shoham D, Kramer H. Metabolic syndrome and self-reported history of kidney stones: the National Health and Nutrition Examination Survey (NHANES III) 1988-1994. Am J Kidney Dis. 2008; 51:741-747.

29. Draga RO, Kok ET, Sorel MR, Bosch RJ, Lock TM. Percutaneous nephrolithotomy: factors associated with fever after the first postoperative day and systemic inflammatory response syndrome. J Endourol. 2009; 23:921-927.

30. Mariappan P, Smith G, Moussa SA, Tolley DA. One week of ciprofloxacin before percutaneous nephrolithotomy significantly reduces upper tract infection and urosepsis: a prospective controlled study. BJU Int. 2006; 98:1075-1079.

31. Bag S, Kumar S, Taneja N, Sharma V, Mandal AK, Singh SK. One week of nitrofurantoin before percutaneous nephrolithotomy significantly reduces upper tract infection and urosepsis: a prospective controlled study. Urology. 2011; 77:45-49.

32. Petrie HT, Klassen LW, Kay HD. Inhibition of human cytotoxic $\mathrm{T}$ lymphocyte activity in vitro by autologous peripheral blood granulocytes. J Immunol. 1985; 134:230-234.

33. Evan AP, Bledsoe S, Worcester EM, Coe FL, Lingeman JE, Bergsland KJ. Renal inter-alpha-trypsin inhibitor heavy chain 3 increases in calcium oxalate stone-forming patients. Kidney Int. 2007; 72:1503-1511.
34. Evan AP, Coe FL, Rittling SR, Bledsoe SM, Shao Y, Lingeman JE, Worcester EM. Apatite plaque particles in inner medulla of kidneys of calcium oxalate stone formers: osteopontin localization. Kidney Int. 2005; 68:145-154.

35. Hulsmans M, Holvoet P. The vicious circle between oxidative stress and inflammation in atherosclerosis. J Cell Mol Med. 2010; 14:70-78.

36. Iba A, Kohjimoto Y, Mori T, Kuramoto T, Nishizawa S, Fujii R, Nanpo Y, Matsumura N, Shintani Y, Inagaki T, Hara I. Insulin resistance increases the risk of urinary stone formation in a rat model of metabolic syndrome. BJU Int. 2010; 106:1550-1554.

37. Coffelt SB, Kersten K, Doornebal CW, Weiden J, Vrijland K, Hau CS, Verstegen NJ, Ciampricotti M, Hawinkels LJ, Jonkers J, de Visser KE. IL-17-producing gammadelta T cells and neutrophils conspire to promote breast cancer metastasis. Nature. 2015; 522:345-348.

38. Kumsar S, Aydemir H, Halis F, Kose O, Gokce A, Adsan O. Value of preoperative stone scoring systems in predicting the results of percutaneous nephrolithotomy. Cent European J Urol. 2015; 68:353-357.

39. Takata H, Fujimoto S. [Metabolic syndrome]. [Article in Japanese]. Nihon Rinsho. 2013; 71:266-269.

40. Dunne JR, Malone DL, Tracy JK, Napolitano LM. Allogenic blood transfusion in the first 24 hours after trauma is associated with increased systemic inflammatory response syndrome (SIRS) and death. Surg Infect (Larchmt). 2004; 5:395-404. 